\title{
Scenario-based Cost Analysis for Vegetable Grafting Nurseries of Different Technologies and Sizes
}

\author{
Myles Lewis ${ }^{1}$ and Chieri Kubota ${ }^{1,2}$ \\ School of Plant Sciences, The University of Arizona, 303 Forbes Building, \\ Tucson, AZ 85721-0036 \\ Russell Tronstad \\ Department of Agricultural and Resource Economics, The University of \\ Arizona, Tucson, AZ 85721-0023
}

\section{Young-Jun Son \\ Department of Systems \& Industrial Engineering, The University of Arizona, Tucson, AZ 85721-0020}

Additional index words. grafting capital needs, grafting robot, healing cost, operation cost, variable cost

\begin{abstract}
Grafting of fruiting vegetables is a relatively new advent in the United States with promise as a technology to improve both yields and the environment. However, investing in a commercial-sized grafting enterprise requires substantial capital investment and is a risky endeavor. A tool to help evaluate grafting costs for different production technologies and sizes of operation is a useful decision aid for individuals investing in new or modifying existing operations to produce grafted plants. Using a combination of engineering and financial equations, a scenario-based analysis was completed to obtain approximate capital and variable costs per plant for both new and existing production facilities. For exemplary purposes, four scenarios consisting of two different crops (tomato and watermelon) at two production sizes with different technology levels [low-volume manual grafting (one million plants per year) and highvolume fully automated grafting (100 million plants per year)] are presented to compare costs. For simplification purpose, consistent weekly production was assumed in the cost simulation. Total capital costs were $\$ \mathbf{1 1 5 , 1 2 7}$ and $\mathbf{\$ 1 1 8 , 9 7 4}$ for low-volume production for grafted tomato and watermelon plants, respectively. They were \$21.6 million and $\$ 16.7$ million under high-volume production for tomato and watermelon, respectively. Among the four scenarios evaluated, variable costs per plant (costs of plants produced) were lowest for watermelons with high-volume production (\$0.089 per plant), suggesting that production costs of grafted plants could decrease by scaling up production and introducing automation. Sensitivity analyses for high-volume production of tomato showed that the electricity rate, grafting clip price, and grafting robot speed were factors with the greatest influence on costs of plants. Scenario-based cost analysis was shown to be an effective tool for developing strategies to reduce the price of grafted plants.
\end{abstract}

Vegetable grafting was recently introduced in North America and has attracted interest from various stakeholders. The technology has been practiced for hundreds of years since it was first used for increasing the fruit size of gourds in China during the fifth century (Lee and Oda, 2003). It has been nearly 80 years since it was first introduced as a pest management practice for commercial watermelon (Citrullus lanatus) production (Tateishi, 1927).

Received for publication 6 Jan. 2014. Accepted for publication 12 Apr. 2014.

This project was funded by USDA NIFA SCRI (Award Number 2011-51181-30963).

We acknowledge Keita Yoshinaga, IAM-BRAIN, Japan, and Wim van del El, ISO, The Netherlands, for information on grafting robots.

${ }^{1}$ These authors contributed equally to this work.

${ }^{2}$ To whom reprint requests should be addressed; e-mail ckubota@ag.arizona.edu.
Today, grafting is applied to various vegetable species of both Cucurbitaceae and Solanaceae families. The total amounts of grafted plants used in commercial production fields and greenhouses are reportedly 766 million in Korea (estimated in Lee et al., 2010), 550 million in Japan (per survey results conducted by MAFF, 2011), and 130 million in Spain (F. Perez Alfocea, personal communication). These numbers are increasing every year as a result of limited options for addressing soilborne diseases and pests with increasing concern for the environment, sustainability, and food safety. In particular, the quickly approaching phase-out completion of methyl bromide in 2015 among developing countries (UNEP, 1997) is encouraging these countries to use more grafted plants as supplemental control measures to replace currently used methyl bromide applications in addition to the developed countries who were supposed to complete the phase-out by 2005 .
In the United States, grafted tomato (Solanum lycopersicum) seedlings have been used by greenhouse hydroponic tomato growers as a result of increased yields throughout the long production cycle from a more vigorous rootstock (Kubota et al., 2008). These seedlings are typically grown in a so-called "high-tech" greenhouse, often with glass-glazing, advanced climate control system, subirrigation, $\mathrm{CO}_{2}$ enrichment, and supplemental lighting. Nearly all these grafted seedlings for greenhouse production are produced in Canada where more greenhouses and the supporting industries like grafting nurseries are clustered (in British Colombia and Ontario). These nurseries are crucial sources of grafted plants currently used in greenhouses. As an example, all large greenhouse tomato industries in Arizona, Texas, and California purchase millions of grafted plants shipped in from nurseries in British Columbia, Canada, every year. For example, a large commercial greenhouse located in Arizona imports nearly five million grafted tomato plants every year. Price for grafted tomato seedlings (excluding seed costs) in recent years have ranged from $\$ 0.40$ to $\$ 0.90$ per plant for young seedling plugs of two to three true leaf stage to $\$ 1.50$ per mature flowering plant with two side shoots (or "double-headed plants") grown in 4-inch rockwool cubes.

Compared with these Canadian nurseries supplying plants to greenhouses, the controlledenvironment technology level of traditional American nurseries serving open-field producers is relatively low. Quonset-style singleor double-layered polyethylene-covered houses with roll-up side vents and overhead irrigation are the predominant structure type. Plants are typically grown in high density $(\approx 1000$ plants per $\mathrm{m}^{2}$ ) to reduce the cost per plant. The price range for non-grafted conventional seedlings for open-field fresh market tomato is as low as $\$ 0.02$ to $\$ 0.03$ per plant (not including seed costs). Clearly, the current technology and therefore the price used in transplant production for greenhouse and open-field fruiting vegetable production differ greatly. To make the grafting technology viable solution for open-field vegetable production, lowering the price of grafted plants seems to be an important key as demonstrated by Djidonou et al. (2013).

Although the efficacy of grafting has been reported by many research groups worldwide, the implementation (capital input) and operation (variable input) costs are relatively unknown. Among references available, Rivard et al. (2010) analyzed two cases of small nurseries located in the eastern United States who produced $\approx 1,000$ to $\approx 10,000$ grafted seedlings in 2008 and reported that production costs (labor and material costs) per grafted plant were $\$ 0.59$ to $\$ 1.25$, including seed costs. Barrett et al. (2012) estimated grafted seedling costs (labor and material costs) at $\$ 0.78$ per plant (including seeds) for a target production level of 1000 plants. These reports on small grafted plant volumes are valuable because the growing industry segment among U.S. grafting users 
seems to be small farmers. However, the production scales examined were far below what would be relevant for applying this technology as a major pest management tactic for U.S. open-field vegetable production. When the industry attempts to initiate large-scale grafting operations in the United States, "underinvesting" may cause difficulty in maintaining consistent quality products. In addition, the potential for "overinvesting" in unneeded equipment may result in premature failure from lack of unmanageable debt.

Although economic analyses based on the real nursery situation (in situ analysis) are critical for the costs and benefit scenario specific to the cases, a limitation of in-situ analysis is that the outcomes are not scalable or applicable to different cases. Therefore, we developed a set of mathematical models that can be used to simulate the capital and variable costs over various cases considering different technologies and scales of nursery operation and perform sensitivity analyses of selected inputs and key parameters. These models are used also in a dynamic simulation considering potential randomness of events and actions in the operation (Meng et al., 2013). The intention of the present report is to provide the user with s reasonably accurate variable cost per plant and capital cost based on user input and selected scenarios applicable to most commercial nurseries in the United States.

\section{Materials and Methods}

Cost structure and variables. We identified a total of 70 primary and 87 derived variables to estimate the capital $\left(I_{\text {cost }}\right)$ and variable costs per plant $\left(V_{\text {cost }}\right)$ in grafting nursery operations (key variables in Tables 1A and 1B). Primary variables are those directly determined based on the selected production scenario (considering location, scale, and method) and they include, for example, electricity rate (\$ per $\mathrm{kWh}$ ), other utility rate (i.e., natural gas rate), equipment purchase price, annual production scale, wage rate, and tray size. Derived variables are mathematically expressed with one or more primary variables as well as selected coefficients (constants). Examples of derived variables are greenhouse space, healing chamber space, facility construction costs, facility utility costs, and substrate and fertilizer consumption costs. Equations and assumptions used for computing $I_{\text {cost }}$ and $V_{\text {cost }}$ are described below.

Variable cost estimation. Variable cost per plant (also known as cost of plant produced, $\left.V_{\text {cost }}\right)$ is the summation of 1) costs of consumable materials $\left(V_{\text {material }}\right)$; 2$)$ depreciation expense for the capital investment (also known as capital service cost) in grafting equipment and structures $\left.\left(V_{d e p}\right) ; 3\right)$ utility cost $\left(V_{\text {utility }}\right)$; and 4) labor cost ( $\left.V_{\text {labor }}\right)$, estimated per grafted plant to produce.

$$
V_{\text {cost }}=V_{\text {material }}+V_{\text {dep }}+V_{\text {utility }}+V_{\text {labor }}
$$

$V_{\text {material }}$ includes costs for consumable materials; namely, substrate, annual tray replacement, fertilizer, grafting clip, and razor blade cost. Following the standard practice in nursery industry, expenses for purchasing seeds for scion and rootstock are not included in $V_{\text {material }}$ because the seed price varies by cultivar and order size, and also seeds are often directly purchased by the producers (customers for the nursery). Annual tray replacement is estimated based on the general life of the particular type of trays used in the nursery operation. $V_{\text {material }}$ largely depends on the "purchasing power" associated with the size of the operation and method of use (e.g., reuse vs. disposable or premixed substrate vs. mixing its own).

In our cost analysis, we decided to include depreciated cost as part of $V_{\text {cost }}$. Depreciation is generally classed as a fixed cost, but new grafting capital investment costs are variable to a conventional nursery considering a grafting enterprise. Therefore, including $V_{d e p}$ in $V_{\text {cost }}$ allows us to evaluate the cost of production with these tangible assets expensed over their useful life in a rational and systematic manner (Garrison and Noreen, 2000) that varies in accordance with the size of the operation to be selected. However, $V_{\text {dep }}$ could be easily separated out because it is independent from other variable costs ( $V_{\text {material }}$, $V_{\text {utility }}$, and $V_{\text {labor }}$ ). Considering a newly built grafting operation, $V_{d e p}$ includes standard items for a vegetable nursery operation (such as greenhouses and seeding machines) and those specific to vegetable grafting (such as healing chambers and grafting robots). The capital/facility items that we consider are found in the later section of capital costs. Each item has a typical "useful life" according to the available guidelines of the IRS (2012). For example, farm buildings such as a headhouse or warehouse are generally considered as 20year structures, horticultural structures such as greenhouse and germination facilities are for 10 years, and robots and machines are for 7 years (IRS, 2012). The depreciation expense of a piece of equipment or structure would be calculated as follows:

$$
J_{i}=\left(I_{i} \cdot K_{i}^{-1}+I_{i} \cdot 0.04\right) \cdot N_{A C}{ }^{-1}
$$

where $J_{i}$ is the depreciation expense of equipment " $i$ " (or structure) per plant; $I_{i}$ is the cost to build or purchase the equipment $i$ (or structure); $K_{i}$ is the useful life of the equipment $i$ (or structure); and $N_{A C}$ is the annual production capacity (number of plants per year). We took an annuity approach and considered including $4 \%$ interest in computing $J_{i}$. Use of a $4 \%$ interest rate was decided based on the 10-year inflation indexed treasury bonds over years 2003-08. We also assumed that salvage value for equipment was zero.

For initiating a new operation, it is often necessary to acquire enough inventories of supplies to start and run the operation for a period of time. Therefore, we consider this "first year start-up material cost" $\left(I_{\text {start }}\right)$ as part of initial costs and thereby $V_{d e p}$. The $V_{d e p}$ can be therefore expressed as:

$$
V_{\text {dep }}=\sum J_{i}+I_{\text {start }} \cdot N_{A C}^{-1}
$$

$V_{\text {utility }}$ is the summation of all the utility costs (except water) to run facilities and equipment used during production, estimated per plant. Water costs were excluded in our scenarios assuming that per-plant water cost becomes negligible but could be added based on the annual water use expected for the areas where costs for water are more significant. Utility rates (price per kWh of electricity, for example) were based on an average commercial utility rate per year by location (i.e., state) for the year 2012 and did not reflect monthly or seasonal fluctuations that may occur by city. Electric utility consumption was calculated based on projected use (operation hours) and the corresponding average electricity rate by location (EIA, 2012). The operating utility (electricity) cost of each piece of equipment (such as the seeder and grafting robot) was calculated using the manufacturer-listed power consumption and the expected weekly operation hours of each piece of equipment based on the expected weekly production and total machine capacity (the individual machine capacity multiplied by the number of units). The operating utility costs for greenhouse, germination chamber, and healing chamber are largely affected by the type of systems selected for each scenario. Furthermore, they are varied by season and by location of the operation, which required the most cumbersome computation, and therefore we used available protocols or resources to simplify the computation.

Greenhouse utility costs for heating a selected site were estimated using heating degree-days (Anonymous, 2009) based on location and season and selected greenhouse design specifications affecting its thermal properties. In addition to greenhouse heating, there is a greenhouse electric power operating expense. This value considers the use of pumps, fans, and other equipment in the greenhouse. Among the limited information, we have identified two greenhouse energy audit reports publically accessible (Anonymous, 2003; Johnson, 2003). As a result of the 10 -fold difference between the two reported values, presumably caused by the difference in technologies used in these greenhouses, an average of these values was used in our analysis. Computation was based on total operating days per year of these facilities at the selected average energy consumption.

Most commercial germination and healing facilities are run by electricity (heating, cooling, humidifying, and lighting). Consumption of electric power $(\mathrm{kWh})$ per plant for germination and healing chambers was theoretically estimated using a base expense (dollars per chamber foot print) of a unit-sized chamber under selected steady-state conditions $\left[29^{\circ} \mathrm{C}\right.$ and $95 \%$ relative humidity $(\mathrm{RH})$ inside the chamber, and $15{ }^{\circ} \mathrm{C}$ and $50 \% \mathrm{RH}$ outside the chamber], chamber size and number, tray size and cell density used, and number of plants processed at a time. The electricity costs of these chambers were computed based on weekly operation hours and the electricity rate of selected locations.

$V_{\text {labor }}$ is the summation of the all labor directly involved in the production of grafted plants. In our analysis, average labor cost was 


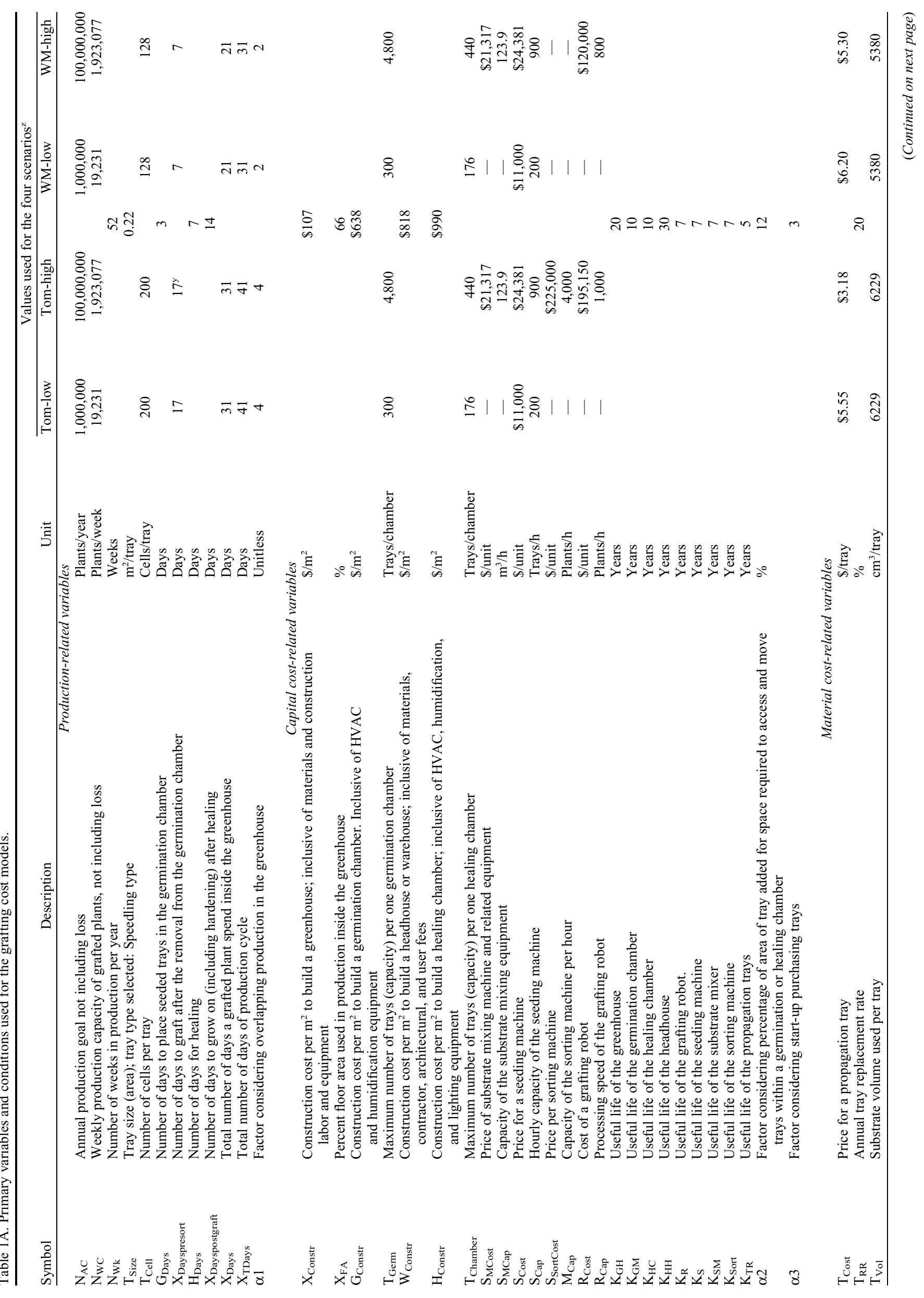




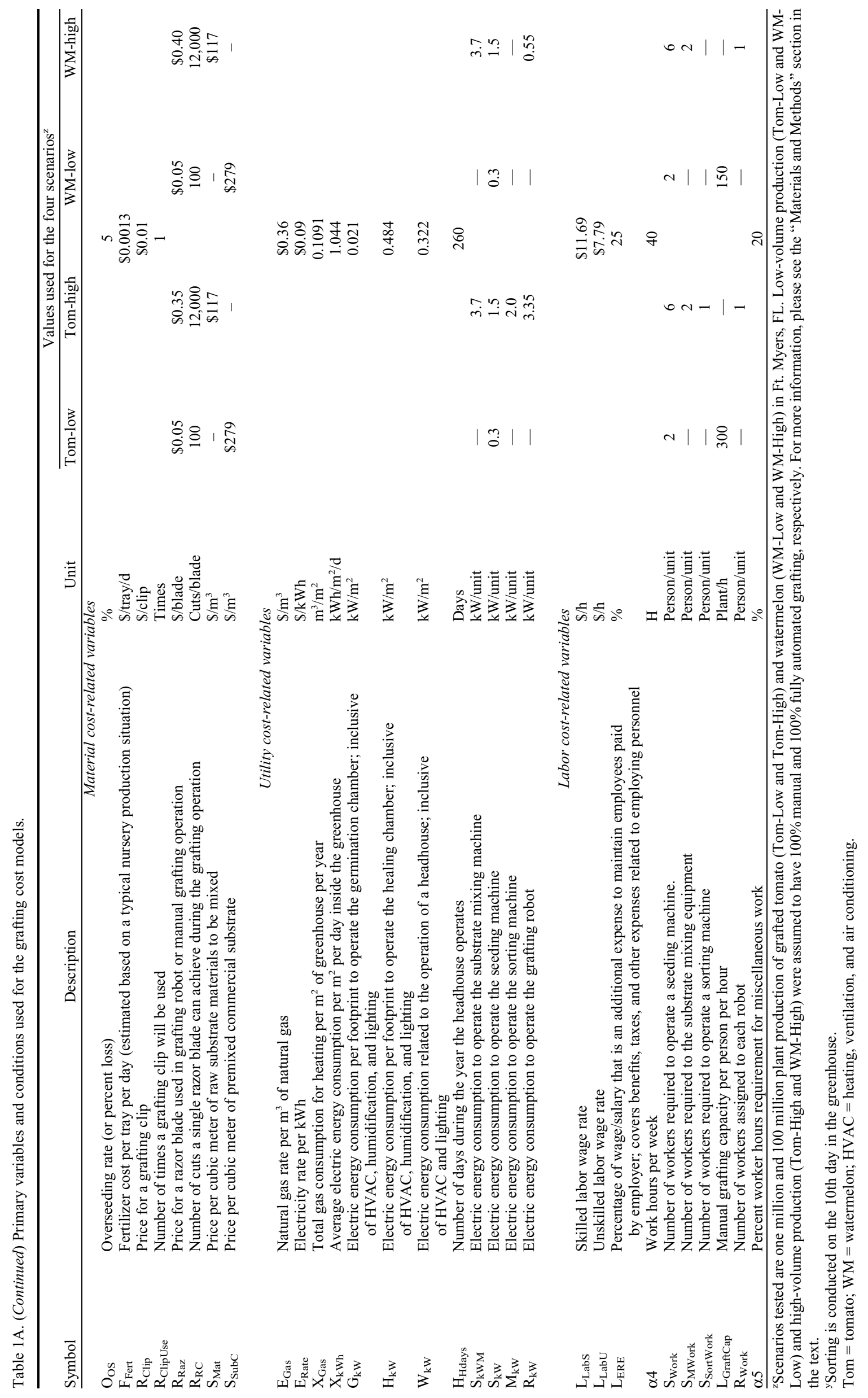




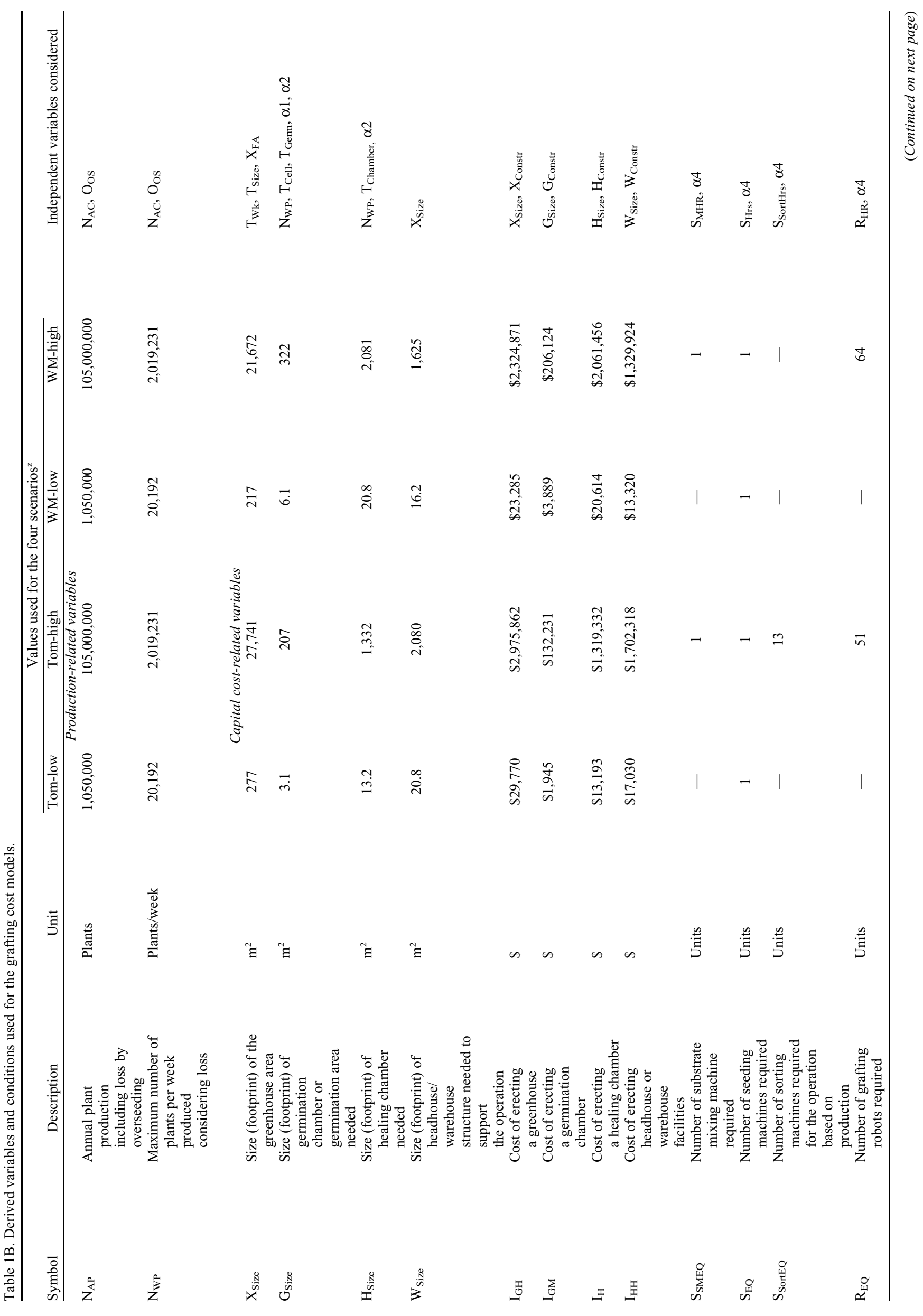

HortSCIENCE Vol. 49(7) July 2014 


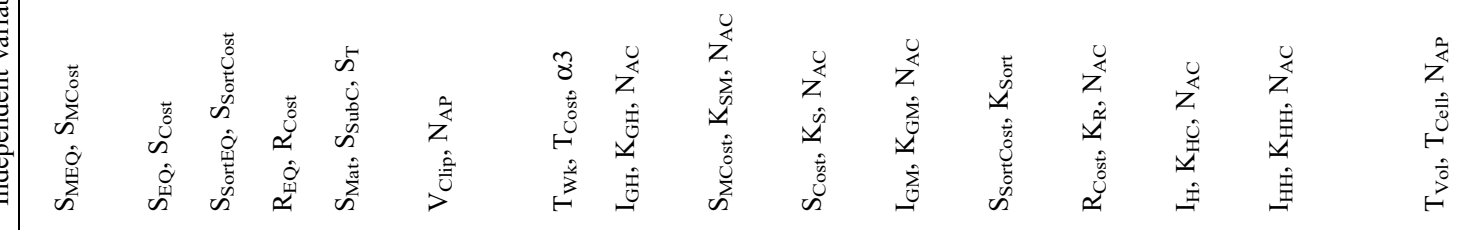

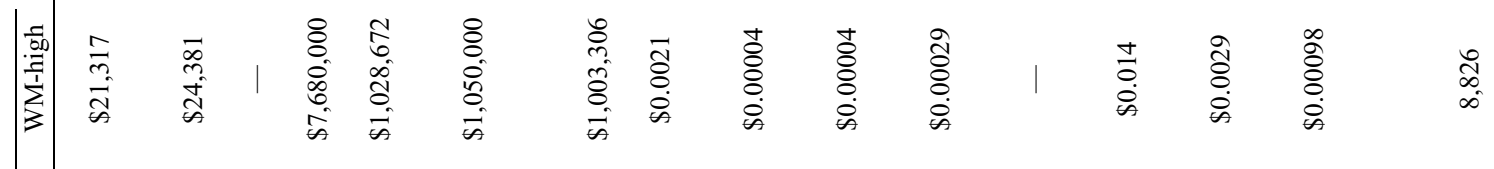

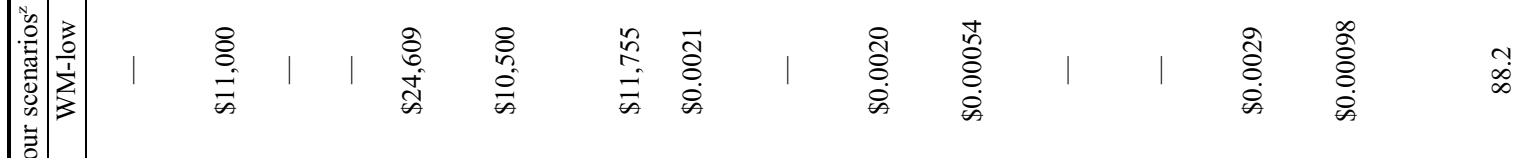

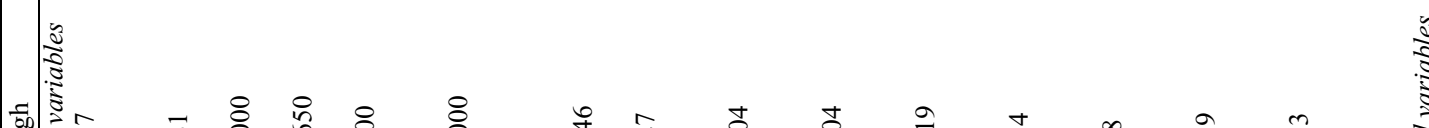

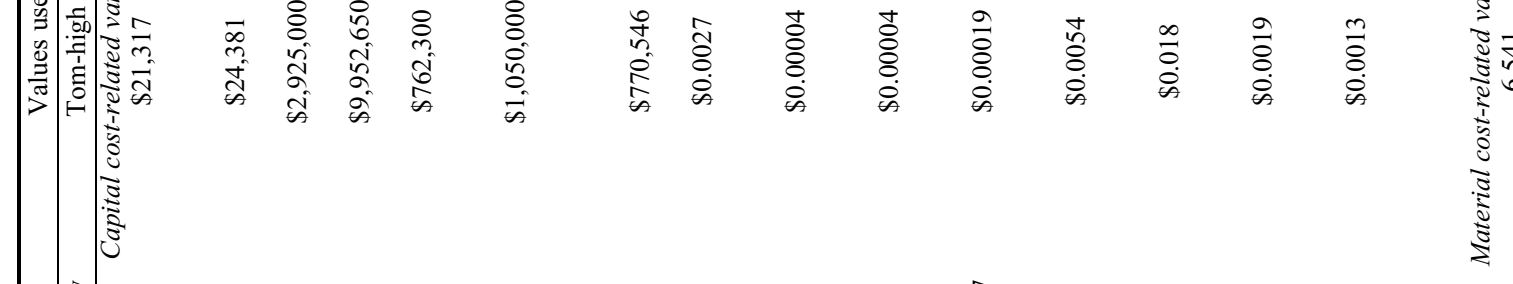

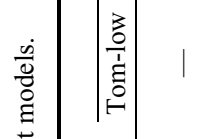

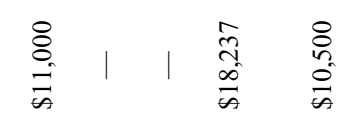

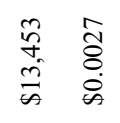

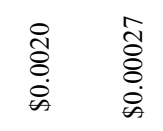

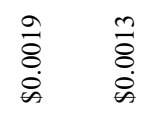

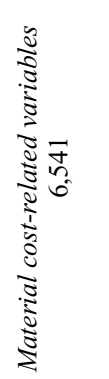

惫

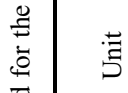

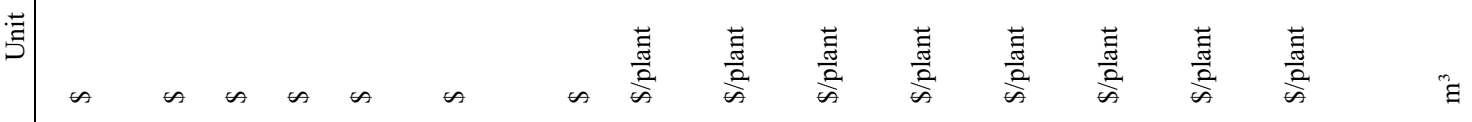

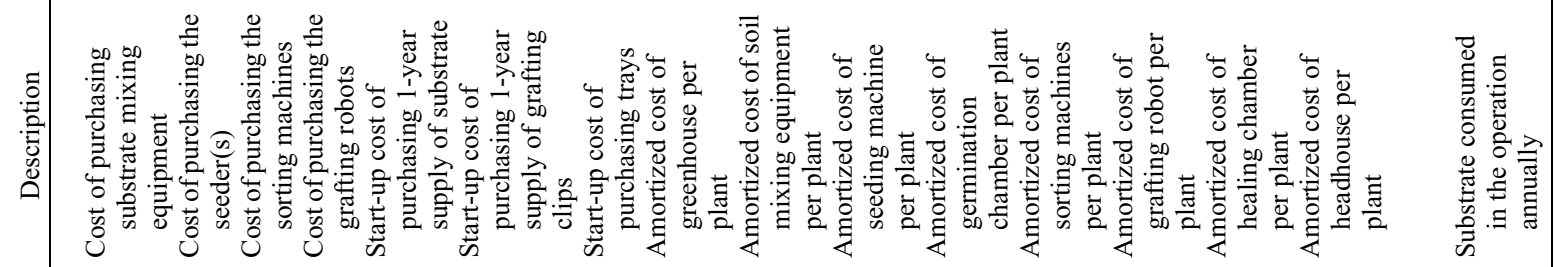

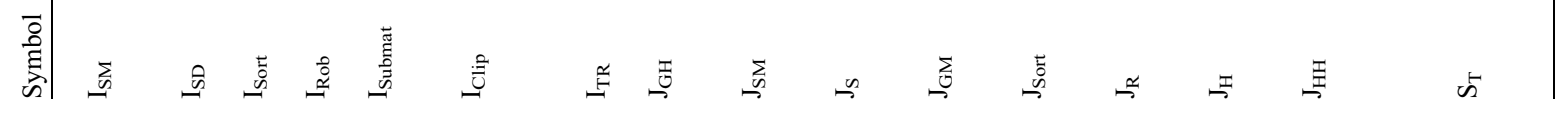




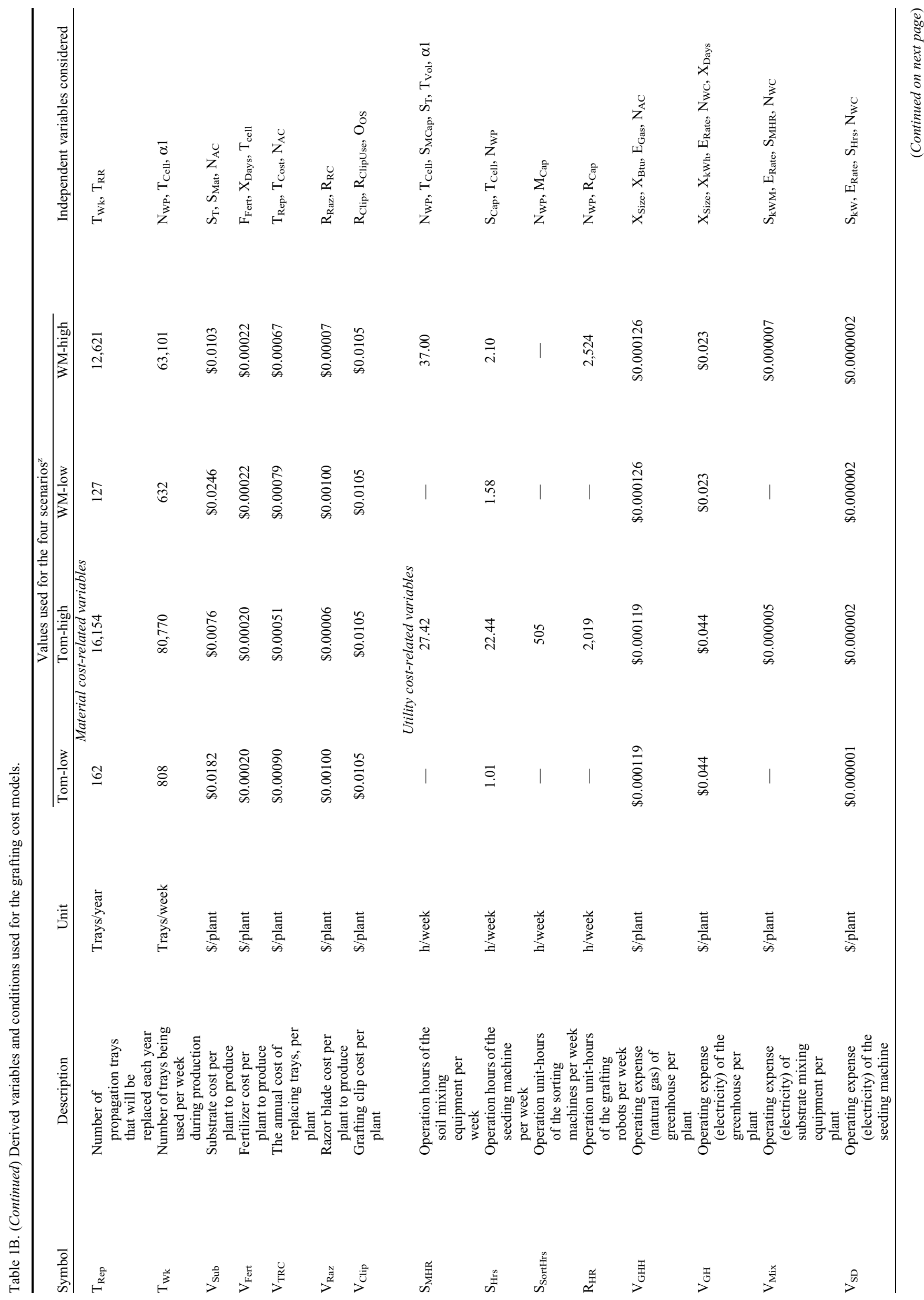

HortScience Vol. 49(7) July 2014 


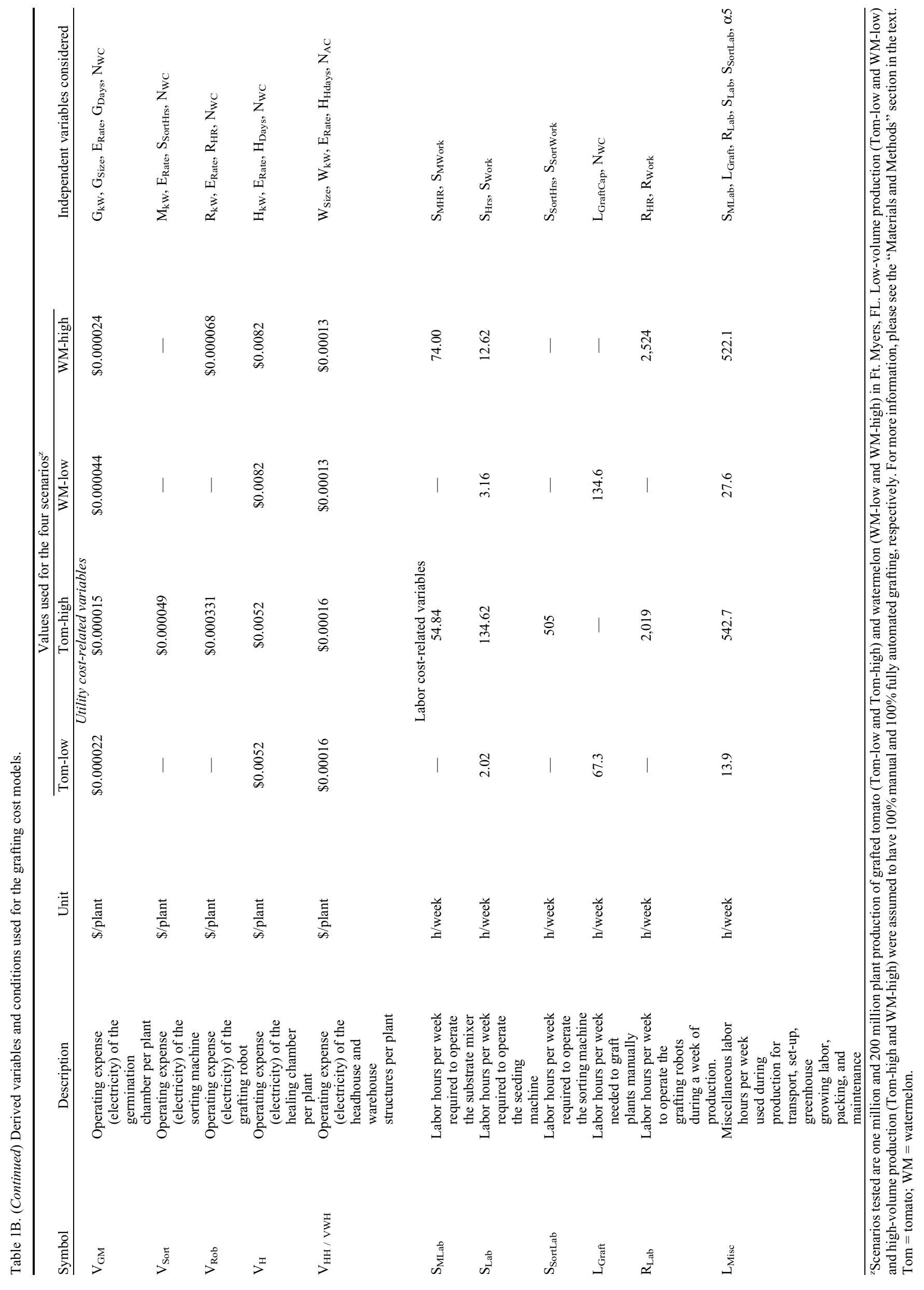


computed based on the typical labor requirement over a single cycle (from seed to finishing) of grafted seedling production. Specifically, we considered the labor hours and rates for 1) tray and substrate preparation; 2) seeding or attending seeders; 3 ) attending sorting machines (if used); 4) grafting or attending grafting robots (if used); and 5) miscellaneous tasks (including greenhouse management and equipment maintenance). Using a given target production scale per week, we estimated these labor hours input and rate for each step considering the other conditions selected for the scenarios (such as use of automation) and then computed the cost per plant. Miscellaneous labor was assumed to be $20 \%$ of all other labor hours. The labor cost includes wages and fringes [employee related expenses $\left(L_{E R E}\right), 25 \%$ in the present study, Table 1A] but does not consider management overhead and SG \& A (selling, general, and administrative) costs in our analysis. We also considered classification of skilled vs. unskilled labor for tasks and assigned differing wage rates for each. Unskilled workers engage in activities such as seeding, substrate mixing, cleaning, attending robot, and miscellaneous labor at rates equivalent to minimum wage or otherwise set by the user. Skilled workers engage in activities such as manual grafting, sorting, and operation of complex machinery such as a tractor or forklift at wage rates above minimum wage by $50 \%$ according to prevailing wage rates of a similar category.

Capital cost estimation. Capital cost $\left(I_{\text {cost }}\right)$ consists of conventional nursery facilities/ equipment costs $\left(I_{\text {seedling }}\right)$ and those for the grafting specific facilities/equipment $\left(I_{\text {graft }}\right)$. By structuring the cost equation with distinct terms for conventional and grafting operations, our economic analysis became more flexible and allowed existing nurseries to estimate the additional cost to acquire grafting capability.

$I_{\text {seedling }}$ is generally determined by the weekly production capacity. Capital cost items associated with $I_{\text {seedling }}$ are 1) substrate mixing equipment; 2) seeding machine; 3 ) germination chamber; 4) greenhouse; 5) warehouse; 6) headhouse; 7) other special equipment; and 8) start-up materials. Start-up materials are required to begin the operation and often considered as a 1-year supply of substrates and trays. For example, annual supply of substrate required was estimated from the number of scion and rootstock plants produced per year, tray cell volume, and production loss. Other special equipment can be a low-temperature storage chamber, automatic transporters, and seedcoating machines; however, none of them were included in our present analysis because they are not necessarily considered standard items.

Capital cost items associated with $I_{\text {graft }}$ are 1) sorting machine; 2) grafting robot; 3 ) healing chamber; 4) other special equipment; and 5) grafting-specific start-up materials. A sorting machine seems to be common equipment for a tomato grafting operation in The Netherlands and Canada where the largescale grafting operations currently exist. This is because interspecific tomato rootstocks widely used for greenhouse tomato have limited uniformity in germination/emergence. Sorting at the cotyledon stage results in more uniform stands for each tray, contributing to enhancing grafting efficiency. Start-up materials included in the $I_{\text {graft }}$ were grafting clips and razor blades. A 1-year supply of grafting clips and razor blades was determined by annual number of grafted plants produced, production loss, and number of cuts performed per razor blade.

There were some limitations regarding the selection of equipment and machines. Equipment prices were obtained based on the catalogues and sales quotations and restricted by the models available in the current market. Equipment models and the necessary number of the units were selected among those available in the current market to meet the highest weekly volume of production assuming that the machine can work at the highest capacity specified by the manufacturer. However, it may not always be operated at that capacity, which will result in fluctuations of energy and operating cost.

Costs for greenhouses are dependent on the size of facility and the technology. Greenhouse technologies are generally classified into three levels. The high-technology level applies to a Dutch Venlo greenhouse that is glazed with glass or a semipermanent glazing material and equipped with an integrated climate control system to activate heating, cooling, $\mathrm{CO}_{2}$ injection, supplemental lighting, and irrigation systems. The low-technology level applies to a greenhouse that is glazed with one or double layers of plastic film such as polyethylene film and is not equipped with any heating system. Climate control may be done with a simple thermostat to control the vents. High tunnels can be included in this category. The medium-technology level is anything between these two categories, including a greenhouse covered with rigid plastic sheets (such as polycarbonate or double acrylic panels) with active heating and cooling systems. Greenhouse and headhouse sizes were determined based on the space needed during the peak production season when maximum use of these facilities is expected. Generally, to consider the greenhouse space, we had to consider overlapping production cycles at any given week to be able to sell the finished products (trays of grafted plants) at a weekly basis. To simplify, we assumed that the same number of plants are produced weekly during the peak production season. Therefore, the required size could be estimated from the maximum weekly number of trays produced per week (scion and rootstock, including loss), number of overlapping producing cycles, unit tray size, and the percent floor area of greenhouse usable for production (66\%; Aldrich and Bartok, 1994). The cost of erecting a greenhouse was found from manufacturers' catalogs and through personal communication per technology level selected for the scenario. Size of the headhouse and warehouse was determined based on the suggested assumption of $7.5 \%$ to $13 \%$ of total greenhouse space by Aldrich and Bartok (1994), where the smaller percentage was suggested for a larger operation. The cost of erecting a headhouse/warehouse structure was found from the existing resource (REED construction data; Anonymous, 2013)

Costs for constructing germination chamber and healing chamber were estimated based on the size and design needed to complete the expected weekly task. Germination chamber size was based on maximum weekly production (number of scion and rootstock plants including loss), percent floor area usable ( $89 \%$ in our present study), and tray size and cell density. In our analysis, we assumed that nurseries use an indoor unit that has the capacity to hold seeded trays stacked up to 25 tray layers. We also had to set a minimum capacity per chamber acceptable for each scenario and estimated the required chamber foot print size. As a first step of cost estimation, we selected a germination chamber as the design base to compute the facility cost per unit size $\left(\mathrm{m}^{2}\right.$ footprint size $)$ including the construction cost. Then, the total facility cost needed for a scenario-specific production size was estimated based on the required size (in total foot print) and the facility cost per unit size (estimated using the design base). The healing chamber we used in our cost analysis was also an indoor unit with artificial lighting installed. The chamber size and facility cost were determined in a similar manner as for the germination chamber. However, healing chambers involved more engineering design to meet the requirements of environmental conditions (light intensity, air temperature, and $\mathrm{RH}$ ), as described below.

Chamber designs used as the base to estimate costs. The chamber size used as the design base of germination chamber and healing chamber was $7.6 \mathrm{~m} \times 7.6 \mathrm{~m} \times 3.7 \mathrm{~m}$ having a $214-\mathrm{m}^{3}$ volume. The chambers were standard insulated modular structures with walls made of insulated panels $(10 \mathrm{~cm}$ thickness) to minimize the energy consumption. We assumed that these chambers were placed inside a warehouse building with minimum protection from the outside climate.

The cost of building a germination chamber was quoted from a commercial source for prefabricated insulated structures and included the costs found for heating and humidification equipment having the capacity that was computed under the selected conditions described below. The capital cost specific to the germination chamber was converted to the cost per unit size of footprint $\left(\mathrm{m}^{2}\right)$. There was no major lighting inside the germination chamber (other than access lighting for workers). Heating and cooling requirements were estimated based on the expected air temperature and relative humidity inside and outside the chamber. Typical germination conditions for tomato and cucurbit scion and rootstock seeds $\left(29{ }^{\circ} \mathrm{C}\right.$ and $\left.95 \% \mathrm{RH}\right)$ were used for the inside condition. Outside conditions (inside the warehouse) were $15^{\circ} \mathrm{C}$ and $50 \% \mathrm{RH}$. Therefore, germination chambers under these conditions require electric 
heating only. Based on the energy balance of the germination chamber, any potential loss of heat resulting from the ventilation/infiltration as well as overall heat transfer through the wall, was made up with the output from the electric heating. The base design resulted in a $0.021 \mathrm{~kW}$ per $\mathrm{m}^{2}\left(G_{K W}\right.$, Table $\left.1 \mathrm{~A}\right)$.

In the healing chamber used for our design base, there were four shelving units equipped with luminaires. Each unit had five layers a piece with a size of $7.6 \mathrm{~m}$ (width) $\times$ $0.9 \mathrm{~m}$ (depth) $\times 0.6 \mathrm{~m}$ (height). Electrical power consumption by the healing chamber was by lighting, cooling, humidification, and heating. When the lights were turned on inside a well-insulated chamber, heating was not necessary except during the time when the plants were maintained in darkness (the first $24 \mathrm{~h}$ ). Number of luminaires to obtain target light intensity over the plant canopy $\left(50 \mu \mathrm{mol} \cdot \mathrm{m}^{-2} \cdot \mathrm{s}^{-1}\right.$ photosynthetic photon flux) was estimated following the procedure used by Ohyama and Kozai (1998). Briefly, it was estimated based on the shape of each shelf, reflectance of each surface of the shelf, and the effective photosynthetically active radiation photon emission rate of luminaires $\left(\mu \mathrm{mol} \cdot \mathrm{s}^{-1}\right.$ per luminaire, 400 to $700 \mathrm{~nm}$ ). We assumed that the ordinary white fluorescent lamps (32 W, T8 type) were used in the healing chamber. Based on the total electric power used for lighting, estimated heat exchange through ventilation/infiltration, and overall heat exchange through the walls, the net balance was computed as the cooling load. The electric power consumption for cooling was estimated using the cooling performance of the selected cooling unit [coefficient of performance (COP)] available from the manufacturer (i.e., $\mathrm{COP}=2.93$ in this study). Heating becomes necessary when the lights are off during the first $24 \mathrm{~h}$ of the $7-\mathrm{d}$ healing process. Typical healing conditions $\left(29^{\circ} \mathrm{C}\right.$ and $\left.95 \% \mathrm{RH}\right)$ were used for the inside condition. Outside conditions (inside the warehouse) were $15^{\circ} \mathrm{C}$ and $50 \% \mathrm{RH}$. The heating load was also estimated similarly based on the energy balance of the healing chamber. The electric power consumption for heating was estimated based on the heating performance of the unit selected for the base design.

The healing chamber of the design base was also equipped with humidifiers. The amount of water needed for humidification was included in the cooling load and was estimated from the potential condensation rate (or dehumidification rate) occurring in the evaporator of the cooling unit. The condensation rate was estimated based on the assumption that the outgoing air from the cooling unit had $10{ }^{\circ} \mathrm{C}$ air temperature with saturated humidity. Potential exchanges of water vapor by plants as well as the chamber infiltration were assumed to be negligible compared with the loss of water vapor by the cooling unit. The base design analysis resulted in $0.484 \mathrm{~kW}$ per $\mathrm{m}^{2}$ when lights are used $\left(H_{K W}\right.$, Table 1A).

Data collection. Reference data for cost estimation were obtained through a variety of sources including: published information, personal communication with existing operations and growers, academic peers, manufacturers, distributors, wholesalers, and retailers and Internet and paper catalogs. Site visitations with commercial nurseries were conducted in Dec. 2011 and Mar. 2012. A large-scale grafting nursery in Canada was visited to evaluate an existing high-volume grafted seedling operation (nine to 12 million grafts per year) that serves greenhouse producers. A large-scale conventional nursery in Florida $(\approx 100$ million plant production per year) was visited to evaluate a conventional highvolume transplant production operation that produces seedlings (non-grafted) used in open-field production. During both visits, data were recorded to reflect the operational set-up and equipment used during production. Company performance metrics and operational data collected by the authors included labor input and turnover, typical wage rates and fringes, typical selling price, selected material cost, annual production volume and peak seasons, and logistic information.

Selected scenarios. Four scenarios consisting of two different production sizes/ technologies and two crops (tomato and watermelon) were identified to estimate the costs in a grafting nursery operation as described below. Key primary and derived variables are listed with selected values in Tables 1A and 1B.

Low-volume production with manual grafting tomato and watermelon. These production scenarios had an annual capacity of one million grafted tomato or watermelon plants. For simplification, we assumed that their production was year-round (52 weeks) without a particular peak season. Therefore, weekly production capacity is 19,231 grafted plants. The selected location was Ft. Myers, FL, because of the existing strong industry of fresh-market tomato and watermelon. A medium-technology greenhouse design, having plastic roof glazing, rigid sidewalls, and heating and cooling equipment, with a basic control system, was considered. These scenarios assumed 100\% manual grafting (no robots) using all skilled laborers. In these scenarios, no sorting machine was used and therefore the grafting speed for tomato of the skilled laborers was assumed to be 300 plants per hour, $\approx 75 \%$ of what we verified in a commercial operation with use of a sorting machine and well-designed logistics. The grafting speed for watermelon was assumed to be 150 plants per hour. A pre-mixed commercial substrate was used, eliminating the need for substrate mixing equipment. As a result of low volumes of materials used in the scenario, buying power was assumed to not exist, and therefore higher prices per unit were expected to occur on items such as propagation trays and substrate, for example.

High-volume production with fully automated grafting tomato and watermelon. These production scenarios had an annual capacity of 100 million grafted tomato or watermelon plants. Although nurseries supplying plants for open fields should have high and low production seasons, in our present study, we also assumed that there was no particular production peak as the first attempt to estimate costs. Weekly production capacity was $1,923,077$ grafted plants. The same location (Ft. Myers, FL) and greenhouse technology level (medium) as in the low-volume production scenarios were selected. These scenarios assumed automatic grafting robots (1000 and 800 grafts per hour for tomato and watermelon, respectively) used with a single unskilled employee assisting each robot. As a result of the volume of production, a higher output seeder (900 trays per hour) was selected for use. Bulk purchasing power was assumed in these scenarios because quantities of inputs purchased will be larger than normal retail-priced orders. Raw substrate materials were assumed to be purchased and mixed on-site using a substrate mixer. For tomato, sorting machines were introduced, following the current greenhouse nurseries practices, to achieve uniform rootstock stands at the time of grafting. In the present scenario, only rootstock seedlings were subject to sorting because they are less uniform than scion seedlings.

All scenarios assumed the two speciesspecific production cycles. For tomato, young tomato seedling plugs having two to three true leaves were produced with a production cycle consisting of $20 \mathrm{~d}$ to graft (including $3 \mathrm{~d}$ in germination), 1 week to heal after grafting, and 2 weeks to grow-on before shipment. For watermelon, young watermelon seedling plugs having two to three true leaves were produced with a production cycle consisting of $10 \mathrm{~d}$ to graft (including $3 \mathrm{~d}$ in germination), 1 week to heal after grafting, and 2 weeks of grow-on before shipment. Plant growth rate is largely affected by greenhouse environmental conditions; however, in the present analysis, we assumed that the production cycle was the same and independent from seasonal variations.

Sensitivity analysis. A basic sensitivity analysis was performed to determine the effect of varied costs of selected items on variable cost per plant based on the highvolume production scenarios. The selected variables chosen are: greenhouse construction cost, healing chamber construction cost, grafting robot price, grafting robot speed, electric power rate, substrate price, grafting clip cost, and unskilled laborer wage rate. In each instance, a single variable was changed to reflect a range of values and their effect on the overall costs.

\section{Results and Discussion}

Capital cost for low- and high-volume production. Capital costs or investment dollars needed for low- and high-volume production for tomato were $\$ 115,127$ and $\$ 21,635,936$, respectively (Table 2 ). Of these, $\$ 25,348$ and $\$ 15,412,454$ are $I_{\text {graft }}$, or grafting-specific capital costs, and they represent $22 \%$ and $71 \%$ of total capital costs $\left(I_{\text {cost }}\right)$ (data not shown). For watermelon, the $I_{\text {cost }}$ were 
$\$ 118,974$ and $\$ 16,730,052$ for low- and high-volume production, respectively. The $I_{\text {cost }}$ was greater for watermelon than tomato with a low volume of production, mainly as a result of the greater areas needed for the expensive indoor building structures (healing and germination chambers) attributable to its lower planting density ( 128 vs. 200 cells per tray). However, the areas needed for a greenhouse and headhouse were smaller for watermelon than tomato as a result of the shorter production cycle ( $31 \mathrm{~d}$ vs. $41 \mathrm{~d}$ ), creating less overlapping production cycles and lower costs. Nevertheless, the decrease in costs resulting from the smaller greenhouse/ headhouse space requirement was not large enough to balance the increase caused by the larger healing and germination chamber space requirement, increasing the $I_{\text {cost }}$ for watermelon compared with tomato at this low-volume production scenario. In contrast, for the high-volume production scenario, the $I_{\text {cost }}$ became greater for tomato than for watermelon, mainly as a result of the introduction of a sorting machine and the greater cost for introducing grafting robots for tomato. Sorting machines may be eliminated by improving the uniformity of seedlings. Typically interspecific hybrid rootstocks (Solanum lycopersicum $\times S$. habrochaites), the most widely used rootstock for tomato, are less uniform in seedling establishment, whereas they are vigorous and therefore preferred for tomato growers. When vigor is not the primary goal of grafting, intraspecific hybrid rootstocks (Solanum lycopersicum) are acceptable and they can develop uniform stands without using sorting machines. Elimination of a sorting machine will reduce the total capital input by $13.5 \%$ for tomato in large-volume production, bringing $I_{\text {cost }}$ down to $\$ 18,710,936$.

The largest capital cost item is start-up materials (36.6\% to $39.4 \%$ ) for low-volume production and the grafting robots $(45.9 \%$ to $46.0 \%$ ) for high-volume production. Of the start-up materials, the largest spending was for substrate $(\$ 18,237$ for tomato and $\$ 24,609$ for watermelon) followed by trays (\$13,453 for tomato and $\$ 11,755$ for watermelon) (Table 1B).
Healing chambers were also recognized as large capital cost items in our analysis (11.5\% to $17.3 \%$ and $6.1 \%$ to $12.3 \%$ for lowand high-volume production, respectively). The construction costs for the indoor healing system are more expensive than for a greenhouse-based healing system. However, the advantage of an indoor healing system is the consistency of the results (i.e., high grafting success rate) because there is minimum spatial and temporal fluctuation in the conditions inside the chamber. For this reason, commercial nurseries in Japan and Korea are now not only using the indoor facilities for healing, but also growing scion and rootstock seedlings under artificial lighting (Ohyama and Kozai, 1998). However, when minimizing capital costs has a higher priority than designing the optimum production facility or obtaining the highest success rate (minimum loss), the elimination of healing chamber costs and adding the necessary area for healing into the greenhouse area may result in the reduction of the total capital input by $\approx 10 \%$ and $\approx 15 \%$ in low-volume production and $\approx 5 \%$ and $\approx 10 \%$ in high-volume production for tomato and watermelon, respectively. Nevertheless, this reduction of $I_{\text {cost }}$ through eliminating the indoor healing chamber could affect the variable costs in multiple ways. First, the greenhouse operating expense $\left(V_{G H H}\right.$ and/or $\left.V_{G H}\right)$ may increase as the additional time $(7 \mathrm{~d})$ in greenhouse and additional environmental control systems to create conditions suitable for healing. The magnitude of increase could be depending on the location and season to produce the grafted plants. In a mild climate in Florida, it most likely results in the increase in the greenhouse electricity cost, $V_{G H}$, to eliminate the heat accumulating inside the greenhouse while maintaining the high humidity. Second, $V_{H}$, the indoor healing electricity, could be eliminated. However, because the greenhouse electricity cost is the largest utility item, this potential reduction in $V_{H}$ may not be large enough to compensate the increase in $V_{G H}$. Third, a greater loss of plants should be expected. The loss could be larger in watermelon than in tomato because grafted watermelon plants generally require better controlled healing conditions in our experience. Johnson and Miles (2011) demonstrated the varied success rates when different designs of healing system were used. They also found that tomato grafting achieved a higher success rate (greater than $95 \%$ ) regardless of healing chamber design than eggplant or watermelon.

Variable cost for low- and high-volume production. First, to validate the accuracy of the results computed using the equations we developed for the nursery costs analysis, we estimated the costs of conventional (nongrafted) seedlings produced in a commercial nursery. A nursery manager anonymously disclosed the sales and their variable costs as $\$ 0.031$ and $\$ 0.025$, respectively, per conventional tomato seedling (excluding the seed costs). Our estimated $V_{\text {cost }}$ for this nursery was $\$ 0.024$ using the site- and operation-specific information that the company shared with us, demonstrating the reasonable accuracy of the cost estimation in our procedures.

Table 3 shows the variable costs per plant for the selected four scenarios computed using the variables shown in Table 1 . For the low-volume production scenario, the total variable cost $\left(V_{\text {cost }}\right)$ for grafted tomato seedlings was $\$ 0.148$ per plant. The highest cost item contributing to this cost was labor ( $40.1 \%$ of $V_{\text {cost }}$ or $\$ 0.059$ per plant) followed by utilities (33.5\% of $V_{\text {cost }}$ or $\$ 0.049$ per plant). Material and depreciation costs $\left(V_{\text {material }}\right.$ and $V_{\text {dep }}$ ) accounted for $20.9 \%$ and $5.5 \%$ of the $V_{\text {cost }}(\$ 0.031$ and $\$ 0.008)$, respectively.

For watermelon, in the low-volume production, the $V_{\text {cost }}$ was $\$ 0.195$ per plant, $32 \%$ more expensive than tomato. This higher price for watermelon than tomato is mainly the result of the greater labor cost ( $\$ 0.118 \mathrm{vs}$. $\$ 0.059$ per plant), originating from the slower manual grafting speed for watermelon than tomato (150 vs. 300 grafts per hour). The weekly labor hours needed for grafting $\left(L_{\text {Graft }}\right)$ were more than $80 \%$ of total labor hours of the week (Table 1B). Furthermore, the 50\% greater wage rate was applied to grafting workers, making the influence of grafting in total labor cost even greater. In contrast, utility cost $\left(V_{\text {utility }}\right)$ was lower for watermelon (\$0.032 vs. \$0.049 per plant), mainly as a result of the shorter production cycle despite the lower cell density considered for watermelon than tomato ( 128 vs. 200 cells per tray). Utility

Table 2. Capital expenditures by item and their percentage relative to the total capital costs for high- and low-volume tomato and cucurbit production in Ft. Myers, FL.

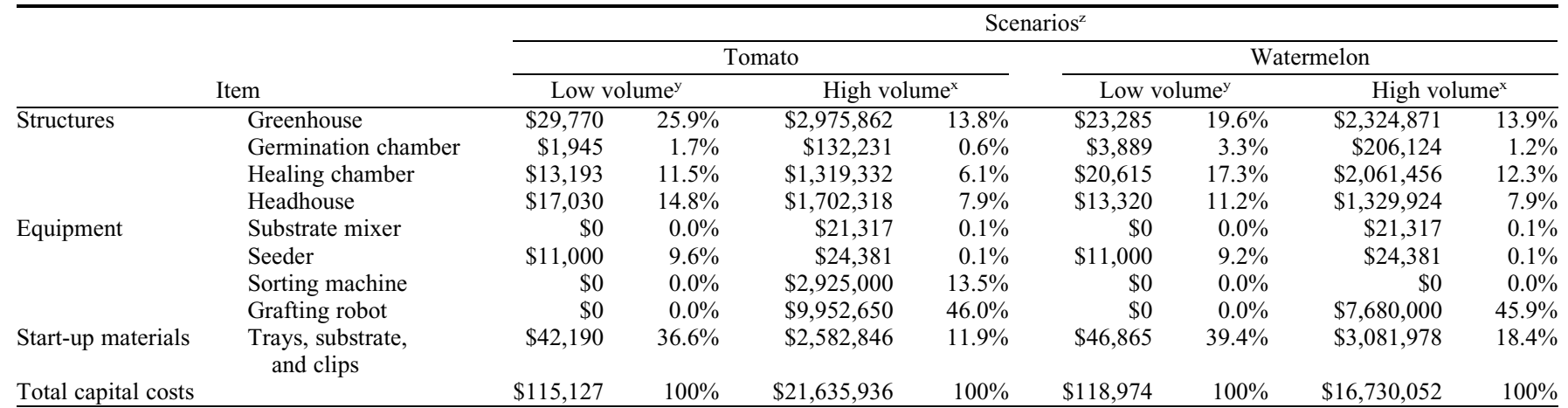

${ }^{\mathrm{z}}$ Four production scenarios in Ft. Myers, FL (see text for further description).

${ }^{\mathrm{y}}$ Weekly production of 19,231 grafted plants $(1,000,000$ grafted plants per year) using manual grafting operation.

${ }^{\mathrm{x}}$ Weekly production of $1,923,077$ grafted plants $(100,000,000$ grafted plants per year) using fully automated grafting operation. 
costs are determined by the duration of each stage of production cycle as well as the cell density (planting density). Lok et al. (2002) demonstrated that cell density was the critical cost factor in estimating electric energy consumption of transplant plugs under artificial lighting when the total production cycle did not change.

In the analysis reported by Rivard et al. (2010), the variable costs for a grafted tomato seedling were $\$ 0.59$ to $\$ 1.25$ per plant (including seeds). Excluding the seed costs reported in their study, the variable costs were $\$ 0.31$ to $\$ 0.93$, of which labor costs were $\$ 0.133$ to $\$ 0.458$ per plant. Similarly, Barrett et al. (2012) reported that the variable cost for a grafted tomato seedling was $\$ 0.78$ per plant (or $\$ 0.45$ per plant without seed costs) including $\$ 0.184$ labor costs per plant. The relatively high costs per plant reported in these studies compared with what we estimated for the low-volume production scenario for tomato are first the result of the higher material costs originating from the low production scale $(\approx 10,000$ plants or less) used in these reports. For example, grafting clip costs were $\$ 0.067$ higher in Rivard et al. (2010) than ours (\$0.01 per piece, the lowest market price for purchasing one million clips). These differences in material costs are caused by limited "purchasing power" associated with the small size of the operation. In addition, heating costs reported by Rivard et al. (2010) for one case were $\$ 0.138$ per plant, whereas ours was only $\$ 0.0001$, reflecting the difference in heating demand in two different locations (Pennsylvania vs. Florida). Another factor causing the large difference in variable costs was the slower manual grafting speed (100 to 200 grafts per hour per person) and, in some cases, greater wage rate (up to $\$ 14.00$ per hour) than what we employed in our analyses (300 grafts per hour and \$11.69 per hour). These low grafting speeds and high wage rate may be reasonable for cases of a small-scale seasonal operation, which are not our intended scenarios. The impact of grafting speed and wage rate is discussed elsewhere in this article.

For high-volume production scenario (100 million plants per year or 1.9 million plants per week), the $V_{\text {cost }}$ for grafted tomato seedlings was reduced to $\$ 0.116$ per plant, showing a $22 \%$ reduction by scaling up the production capacity 100 times. The highest cost item contributing to $V_{\text {cost }}$ at this scale was utilities $\left(42.9 \%\right.$ of $V_{\text {cost }}$ or $\$ 0.050$ per plant). Depreciation and material costs were
$25.5 \%$ and $16.3 \%$ of $V_{\text {cost }}$ or $\$ 0.030$ and $\$ 0.019$ per plant, respectively. The lowest cost item was for labor $\left(V_{\text {labor }}\right)$ accounting for $15.4 \%$ of $V_{\text {cost }}$ ( $\$ 0.018$ per plant). Scaling up the production capacity enabled the introduction of fully automated grafting robots, which contributed to the large reduction in the impact of labor to the $V_{\text {cost }}$, while increasing the depreciation expense. Of the $V_{\text {utility }}$, greenhouse utilities were the highest item that contributed to the cost (Tables $1 \mathrm{~B}$ and 2). The utility costs could be further reduced by better controlling logics for environment or the greenhouse system designs. Of $V_{\text {material }}$, grafting clips and substrates were the two items contributing the most (Table 1B). The sensitivity of $V_{\text {cost }}$ to these cost items is discussed in a later section.

For watermelon, in the high-volume scenario, the $V_{\text {cost }}$ was $\$ 0.089$ per plant, exhibiting a larger reduction of $54 \%$ by scaling up than for tomato. This was the result of the greater impact of introducing grafting robot for watermelon, because the manual grafting speed is slower in watermelon than in tomato (150 vs. 300 grafts per hour). The automated grafting speed used for watermelon and tomato was 5.3 and 3.3 times faster than manual grafting, respectively. The highest cost item for the $V_{\text {cost }}$ was utilities $(35.3 \%$ of $V_{\text {cost }}$ or $\$ 0.032$ per plant) followed by materials $(24.2 \%$ or $\$ 0.022)$. Costs for depreciation and labor were $22.6 \%$ and $17.8 \%$ of $V_{\text {cost }}$ or $\$ 0.022$ and $\$ 0.016$ per plant, respectively. Similar to tomato, greenhouse utilities, grafting clips, and substrates are the major items contributing the $V_{\text {ulitity }}$ and $V_{\text {material }}$ (Table 1B).

As we described earlier, our $V_{\text {cost }}$ does not include the seed costs following the standard nursery practice. Vegetable seed price largely varies depending on the cultivar and the order size. For example, tomato seed scion price can vary between $\$ 0.02$ and $\$ 0.20$ per seed. The tomato rootstock price we found was between $\$ 0.17$ and $\$ 0.25$. These costs will need to be considered when one attempts economic analyses for vegetable producers.

Sensitivity of cost to variable cost factors. Figure 1 shows the effect of selected cost factor (component) on the variable cost $\left(V_{\text {cost }}\right)$ examined under the high-volume production for tomato (100 million grafted seedlings production). The range of values examined for each cost factor was selected primarily based on the lowest and highest price that we found in the market or from available resources. Prices for equipment or facilities that have only a limited number of commercially available models (and therefore there are no lowest and highest prices in the market) were varied within the range that we consider reasonable. An example is the range of grafting robot price, which was varied based on the unit price of a tomato grafting robot $(\$ 195,150)$ per unit.

The cost factor influencing the $V_{\text {cost }}$ the most was grafting clip. This was because grafting clip accounts for a large percentage of $V_{\text {cost }}$ and also because the difference between low and high price found in the market is relatively high (10-fold in our market survey). For example, a grafting clip was as low as $\$ 0.01$ per piece for a tube type made of silicone or some other pliable plastic material and was as high as $\$ 0.10$ per piece for a vendor who sells various horticultural materials to home gardeners and small-scale growers. In fact, Barrett et al. (2012) and Rivard et al. (2010) used $\$ 0.042$ to $\$ 0.077$ for a grafting clip in their grafting cost analyses, relatively close to the high-end price, which is the realistic price for the small-scale operation they examined. Although we selected the lowest price for grafting in our low-volume operation, grafting clip price is a major factor increasing the material cost (Table 1B).

We are also aware that grafting robots have a specific requirement for type and make of grafting clips to use to achieve consistently high performance. However, this limitation could increase the price as a result of the nursery's situation (proximity to the clip suppliers and the volume to purchase). In this analysis, we used the lowest grafting clip price (\$0.01; Table 1A) for both tomato and watermelon. The specific grafting robot model and clips used for the watermelon cost scenario are currently only available in the country of origin, which may result in several cents higher $V_{\text {cost }}$ than presented in Table 3. The relative cost of clip per plant could be further reduced below $\$ 0.01$ if nurseries reuse the grafting clips multiple times. This is a common practice in cucurbit grafting when they use spring-type grafting clips. This practice, however, would add labor costs by increasing necessary labor hours. However, in this tomato high-volume scenario, the labor costs account for $15.4 \%$ of $V_{\text {cost }}$ and the grafting clip price itself $\left(\$ 0.0105\right.$ per plant, $\left.V_{C l i p}\right)$ accounts for $9 \%$ of $V_{\text {cost }}$ (Tables $1 \mathrm{~B}$ and 2 ). Recycled use of a grafting clip may be worth

Table 3. Variable costs per plant and their percentage relative to the total variable costs for high- and low-volume tomato and cucurbit production in Ft. Myers, FL.

\begin{tabular}{|c|c|c|c|c|c|c|c|c|}
\hline \multirow{2}{*}{ Item } & \multicolumn{8}{|c|}{ Scenarios $^{\mathrm{z}}$} \\
\hline & \multicolumn{4}{|c|}{ Tomato } & \multicolumn{4}{|c|}{ Watermelon } \\
\hline Depreciation, $V_{d e p}$ & $\$ 0.008$ & $5.5 \%$ & $\$ 0.030$ & $25.5 \%$ & $\$ 0.009$ & $4.4 \%$ & $\$ 0.022$ & $22.6 \%$ \\
\hline Utilities, $V_{\text {utility }}$ & $\$ 0.049$ & $33.5 \%$ & $\$ 0.050$ & $42.9 \%$ & $\$ 0.032$ & $16.3 \%$ & $\$ 0.032$ & $35.3 \%$ \\
\hline Labor, $V_{\text {labor }}$ & $\$ 0.059$ & $40.1 \%$ & $\$ 0.018$ & $15.4 \%$ & $\$ 0.118$ & $60.4 \%$ & $\$ 0.016$ & $17.8 \%$ \\
\hline Total variable costs, $V_{\text {cost }}$ & $\$ 0.148$ & $100 \%$ & $\$ 0.116$ & $100 \%$ & $\$ 0.195$ & $100 \%$ & $\$ 0.089$ & $100 \%$ \\
\hline
\end{tabular}

${ }^{\mathrm{z}}$ Four production scenarios in Ft. Myers, FL (see text for further description).

${ }^{y}$ Weekly production of 19,231 grafted plants $(1,000,000$ grafted plants per year) using manual grafting operation.

${ }^{\mathrm{x}}$ Weekly production of $1,923,077$ grafted plants $(100,000,000$ grafted plants per year) using fully automated grafting operation. 

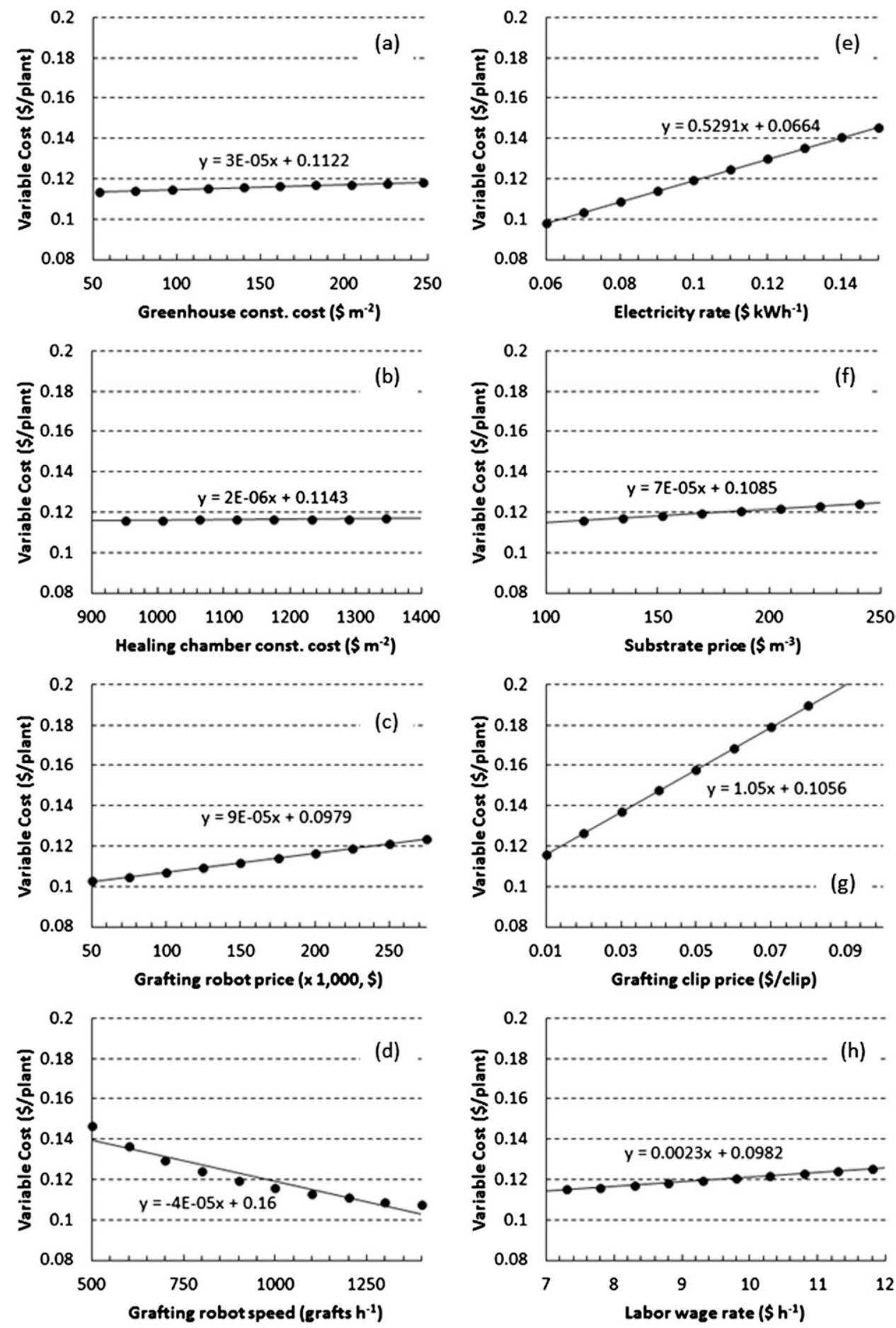

Fig. 1. Responses of variable costs per plant to selected cost factors for the high-volume production of grafted tomato seedlings with fully automated grafting. (a) Greenhouse construction cost $\left(\$ 107\right.$ per $\mathrm{m}^{2}$ as the reference value used in the results presented in Table 1A), (b) healing chamber construction cost (\$990 per $\mathrm{m}^{2}$ as the reference, Table 1A), (c) grafting robot price (\$195,150 as the reference, Table 1A), (d) grafting speed of the robot (1000 per hour as the reference, Table 1A), (e) electricity rate $\left(\$ 0.09 \mathrm{kWh}^{-1}\right.$ as the reference, Table 1A), (f) substrate price $\left(\$ 117 \mathrm{per}^{3}\right.$ as the reference, Table 1A), (g) grafting clip price $(\$ 0.01$ as the reference, Table 1A), and $(\mathbf{h})$ wage for the unskilled labor $(\$ 7.79$ per hour as the reference, Table $1 \mathrm{~A})$. More details of the scenario used for the analysis can be found in the text and Table 1.

considering, particularly for nurseries that could not find a source for reasonably priced clips.

Of interest, the large reduction of grafting robot price examined in the sensitivity analysis (i.e., from $\$ 195,150$ to $\$ 50,000$ ) reduced the $V_{\text {cost }}$ only by $\$ 0.013$ (from $\$ 0.116$ to $\$ 0.103$ ). The relatively small impact of grafting robot price to $V_{\text {cost }}$ is because the expense was depreciated over 10 years and the grafting robot accounts for less than half $(45.7 \%)$ of the total capital cost. In contrast, grafting speed, clip price, and electricity rate largely affected the $V_{\text {cost }}$. This suggests achieving high-quality performance of grafting robots as well as specific requirements in consumable materials, and energy-saving designs, are crucial to lower $V_{\text {cost }}$ in grafting nurseries and thereby the purchase price for end-users of grafted plants. However, to increase the success rate and the consistency in the performance, most existing robot designs assume use of specific materials (clips, trays, and substrate) with limited or no flexibility. Although increasing flexibility to grafting automation is a long-term challenge (Kurata, 1994), and often the high capital costs of 
introducing the automation tend to be a typical issue in designing a large-scale operation, automation manufacturers must design the robot/automation so that it would not increase the material costs although the introduction of low-cost materials may increase the robot price. Introducing robots may not be an effective solution to reduce overall costs, especially when the use of expensive consumable materials (such as clips and substrates) were realized to enhance the grafting speed or reduce the overall system costs.

Increasing and decreasing grafting speed largely impacted $V_{\text {cost }}$. The rather discrete response of $V_{\text {cost }}$ to the grafting speed was because the number of grafting robots required was increased stepwise, rather than continuously, because the current grafting robots are based on a "batch and parallel operation" design rather than "line operation." For a large operation like this scenario, designing the whole system as a line operation may be a more effective approach than the batch and parallel operation with many robots working simultaneously (51 robots in this case). A line operation design could effectively eliminate the redundant use of specific mechanics or devices or optimize the process.

Our cost estimations were based on a selected location in Florida, considering the scale of existing nurseries for fresh-market tomato production. Our preliminary study (data not shown) also suggested that both variable and capital costs were largely affected by operation site for the grafting nursery. The major cost factors associated with site selection were utility rate (electricity and gas), construction cost, and the annual heating requirement. For the site selection of grafting operations, transportation distance and cost need to be considered also. We are currently investigating potential use of grafted cuttings as a means to distribute grafted plant materials to remote locations where grafting capacities are difficult or too expensive to establish. Further cost analysis should be done including this scheme having a primary grafting nursery and secondary nursery to root grafted cuttings.

\section{Conclusion}

Our scenario-based cost analyses demonstrated expected variable and capital costs and their cost influencing factors. A one million grafted tomato plant per year operation could be started with less than $\$ 120,000$ capital investment, whereas a 100 million grafted tomato plant per year production facility requires over a $\$ 20$ million investment, of which $\$ 15$ million are grafting facilityspecific. The variable cost per plant including depreciation expense was estimated as $\$ 0.148$ to $\$ 0.195$ for the low-volume production scenario (one million plant production using manual grafting) and $\$ 0.089$ to $\$ 0.116$ for the high-volume production scenario (100 million plant production using fully automated grafting). In the low-volume production with manual grafting, variable cost was greater in watermelon than in tomato, but the opposite case was observed (tomato $>$ watermelon) when automation was introduced for grafting to process the high volume, as a result of the greater impact of automation in watermelon than in tomato. Preliminary validation by comparing the current market price of seedlings of a large-scale nursery confirmed that our approach and associated costs were reasonably accurate. The cost analyses also helped us to identify the strategies to reduce the price of grafted seedlings further. To understand the cost structure and factors affecting these costs, our intention was to simplify the scenarios. For this reason, yearround constant production was selected for our scenarios. However, more complex dynamic simulation based on expected seasonal fluctuations in demands with associating constraints can be done using a computational approach as we reported earlier (Meng et al., 2013, 2014). Furthermore, these costs and resulting seedling price will be further evaluated in economic analyses of vegetable production of different systems (greenhouses, high tunnels, and open fields) specific to the selected regions and finally in the entire supply chain for cases with and without using grafting technology.

\section{Literature Cited}

Aldrich, R.A. and J.W. Bartok, Jr. 1994. Greenhouse engineering. NRAS-33. Northeast Regional Agricultural Engineering Service, Ithaca, NY.

Anonymous. 2003. Energy conservation opportunities for greenhouse structures. Eugene A. Scales and Associates, Roseville, MN. $<$ http:// www.state.mn.us/mn/externalDocs/Commerce/ Energy_Conservation_for_Greenhouses_ 120503035439_EnergyConservationforGreen houses.pdf>.

Anonymous. 2009. Estimated annual heating cost for greenhouses. In: Extension engineering handbook. University of Georgia, College of Agriculture and Environmental Sciences. <http:/http:// www.caes.uga.edu/departments/bae/extension/ handbook/>.

Anonymous. 2013. Warehouse construction cost estimate (US national average). In: Reed construction data. <http://www.reedconstructiondata.com/ rsmeans/models/warehouse/ $>$.

Barrett, C.E., X. Zhao, and A.W. Hodges. 2012. Cost benefit analysis of using grafted transplants for root-knot nematode management in organic heirloom tomato production. HortTechnology 22:252-257.

Djidonou, D., Z. Gao, and X. Zhao. 2013. Economic analysis of grafted tomato production in sandy soils in northern Florida. HortTechnology 23:613-621.
EIA. 2012. Electric sales, revenue, and price. U.S Energy Information Administration. <http:// www.eia.gov/electricity/sales_revenue_price/ $>$.

Garrison, R.H. and E.W. Noreen. 2000. Managerial accounting. 9th Ed. McGraw Hill, Boston, MA.

IRS. 2012. Farmer's tax guide. Department of the Treasury Internal Revenue Service Publication 225. <http://www.irs.gov/pub/irs-pdf/p225.pdf > .

Johnson, E.L. 2003. Farm energy audit report. DLtech, Inc. <http://www.cornellcea.com/ attachments/CEAGreenhouseEnergyAudit.pdf $>$.

Johnson, S.J. and C.A. Miles. 2011. Effect of healing chamber design on the survival of grafted eggplant, tomato, and watermelon. HortTechnology 21:752-758.

Kubota, C., M.A. McClure, N. Kokalis-Burelle, M.G. Bausher, and E.N. Rosskopf. 2008. Vegetable grafting: History, use, and current technology status in North America. HortScience 43:1664-1669.

Kurata, K. 1994. Cultivation of grafted vegetables. 2. Development of grafting robots in Japan. HortScience 29:240-244.

Lee, J.M., C. Kubota, S.J. Tsao, Z. Bie, P. Hoyos Echevarria, L. Morra, and M. Oda. 2010. Current status of vegetable grafting: Diffusion, grafting techniques, automation. Sci. Hort. 127:93-105.

Lee, J.M. and M. Oda. 2003. Grafting of herbaceous vegetable and ornamental crops, p. 61124. In: Janick, J. (ed.). Horticultural review. John Wiley \& Sons, New York, NY.

Lok, Y.H., K. Ohyama, C. Kubota, and T. Kozai. 2002. Sweetpotato propagule production rate and electric energy consumption in a closed transplant production system as affected by planting density. Journal of Society of High Technology in Agriculture 14:10-17.

MAFF. 2011. Vegetable grafting - Current status and issues. Vol. 7. National Institute of Vegetable and Tea Science, Ministry of Agriculture, Forestry and Fisheries, Japan.

Meng, C., X. Dong, Y.-J. Son, C. Kubota, M. Lewis, and R.E. Tronstad. 2014. An integrated simulation and AHP approach to vegetable grafting operation design. Comput. Electron. Agric. 102:73-84.

Meng, C., Y. Son, C. Kubota, M. Lewis, and R. Tronstad. 2013. Dynamic simulation-based cost analysis for vegetable grafting nurseries. Unpublished report, The University of Arizona.

Ohyama, K. and T. Kozai. 1998. Estimating electric energy consumption and its cost in a transplant production factory with artificial lighting: A case study. J. Soc. High Technol. Agric. 10:96-107[ in Japanese].

Rivard, C.L., O. Sydorovych, S. O'Connell, M.M. Peet, and F.J. Louws. 2010. An economic analysis of two grafted tomato transplant production systems in the United States. HortTechnology 20:794-803.

Tateishi, K. 1927. Grafting watermelon onto pumpkin. Japanese Journal of Horticulture (Nihon-Engei Zasshi) 39:5-8 [in Japanese ].

UNEP. 1997. Report of the ninth meeting of the parties to the Montreal protocol on substances that deplete the ozone layer. United Nations Environment Programme. UNEP/OzL.Pro.9/ 12. 25 Sept. 1997. <http://www.unep.org/ roa/Projects_Programmes/ozone/MB/About/ Report\%20of\%20the\%209th\%20MOP.pdf>. 